\title{
A CONVERSAÇÃO COMO MODO DE DISTINÇÃO NO IMPÉRIO: TESOURO DE MENINOS E CÓDIGO DE BOM-TOM NAS ESCOLAS BRASILEIRAS
}

\author{
Fabiana Sena ${ }^{1}$ \\ Universidade Federal da Paraíba \\ fabianasena@yahoo.com.br
}

\begin{abstract}
RESUMO:
Com o objetivo de tornar visível o que os leitores - crianças, mulheres, homens de diferentes idades da elite brasileira - liam no Oitocentos, este artigo se volta para os livros de civilidade, cujo gênero foi um dos mais freqüentes que circulou no Brasil nessa época, com o intuito de introduzir regras de comportamentos sociais aos interessados a transitar em diversos espaços sociais que surgiam. Para tanto, a conversação foi uma das temáticas da civilidade, a qual esteve presente nos livros desse gênero. Frente aos inúmeros livros que circularam no Brasil na época da Colônia e do Império, elejo duas obras, Tesouro de Meninos (s/d), de Pierre Blanchard e Código do Bom-Tom ou Regras da Civilidade e de Bem Viver no Século XIX (1845), de José Inácio Roquette, para apresentar as orientações do que se deve ou não fazer na conversação, as quais se fizeram presentes também na escola de primeiras letras no Brasil do século XIX.

Palavras-chave: Livros de leitura. Civilidade. Conversação. Império.
\end{abstract}

\section{THE CONVERSATION AS WAY OF DISTINCTION IN THE EMPIRE: TESOURO DE MENINOS AND CÓDIGO DE BOM-TOM IN THE BRAZILIAN SCHOOLS}

\begin{abstract}
:
With the objective of turning visible the one that the readers - children, women and men of different ages of the brazilian elite - read in Eight hundred, this article goes back to the civility books, whose gender was one of the most frequent than it circulated in Brazil in that time, with the intention of introducing rules of social behaviors to the interested parties to transit in several social spaces that you/they appeared. For so much, the conversation was one of the themes of the civility, which was present in the books of that gender. Front to the countless books that circulated in Brazil at that time of Cologne and of the Empire, I choose two works, Tesouro de Meninos (s/d), from Pierre Blanchard and Código do BomTom ou Regras da Civilidade e de Bem Viver no Século XIX (1845), from José Inácio Roquette, to present the orientations than he/she is due or not to do in the conversation, which were made presents also in the school of first letters in Brazil of the century XIX Keywords: Reading books. Civility. Conversation. Empire.
\end{abstract}

\section{Introdução}

A chegada da Família Real no Brasil, em 1808, quando a Corte veio fugida das tropas de Napoleão Bonaparte, que estava para dominar o território Ibérico, sinalizou novos tempos na Colônia, cuja presença da Corte modificou significativamente o cenário cultural e educacional brasileiro ${ }^{2}$. O príncipe regente português, D. João, transferiu para o Rio de Janeiro não somente a Corte, mas toda a burocracia do governo, incluindo os arquivos, a biblioteca real, o tesouro público e aproximadamente 15.000 pessoas, entre 
funcionários do governo e seus familiares (ALENCASTRO, 1997). Com maior concentração populacional no Rio de Janeiro, o governo organizou a cidade, pois, comparada à Metrópole, era atrasada e culturalmente relegada, tomando medidas que possibilitaram desenvolver a vida cultural na Colônia, pois "seria vergonhoso para o rei e para sua corte terem os filhos e parentes 'educados' por escolas e professores como a grande maioria dos que, então, existiam Brasil afora" (TOBIAS, 1986, p. 117).

A chegada da Corte Portuguesa no Brasil, em 1808, foi um marco para o processo civilizador no país. Com um contingente de mais de 15.000 pessoas, D. João VI desembarcou na Colônia - mais precisamente na cidade do Rio de Janeiro -, trazendo uma nova forma de conviver entre os habitantes. Segundo Azevedo (2003, p. 63, destaque do autor), nesse ano,

a cidade vivenciaria um novo estatuto político. Para muito além de uma capital colonial, a cidade transformava-se repentinamente na capital do Império Português, detentor de posses nos cinco continentes da Terra. Para a cidade não só vieram rei, rainha e nobres, como vários órgãos da superestrutura político-administrativa de Portugal. A presença do Estado português fazia-se sentir mais uma vez, no entanto, em novos moldes. Não obstante a entrada dos nobres na cidade já aponta, em termos de significado, as novas demarcações políticas na urbe com o "bota fora", a cidade ganharia em cosmopolitismo, mudança de hábitos, cultura, instituições e economia.

Quanto ao ponto de vista econômico, a Abertura dos Portos favoreceu a queda da taxação alfandegária para as "nações amigas", o que provocou um aumento significativo na entrada de mercadorias. Essa medida acarretou em novas exigências para os setores privilegiados da sociedade, de modo que o luxo e a sofisticação passaram a ser um imperativo para esses setores. Mas esse novo modo de ser e de viver no Rio de Janeiro despertou interesse da classe que habitava a cidade desde antes de 1808, a qual estava entre a massa urbana de escravos e despossuídos e a elite cortesã, que ostentava as suas riquezas pelas ruas.

Impulsionado pela etiqueta e civilidade que ordenavam o jogo das relações na Corte, as quais estavam em vigor na Europa desde o século XVI, D. João VI reorganizou a cidade para o bem-estar da Corte, tomando medidas para o seu desenvolvimento cultural e urbano. Dessa forma, ele criou a Biblioteca Nacional, Jardim Botânico, Museu Nacional, favoreceu a abertura dos portos às nações amigas, a cidade passou a ser arborizada, construiu casas no estilo de Portugal, calçamento e instalou o primeiro banco no Brasil, proporcionando mudanças de hábitos e costumes na população que residia aqui.

Já no Segundo Reinado, sob o governo de D. Pedro II, a Corte passou a ter “calçamento com paralelepípedo (1853), iluminação a gás (1854), rede de esgoto (1862), abastecimento domiciliar de água (1874) e bonde puxados a burro (1859)" (SCHWARCZ, 2007, p. 106). De acordo com Mattos (2004, p. 26), a companhia inglesa, Royal Mail Steam Packet Company, a qual estabeleceu a primeira linha entre a Grã-Bretanha e Brasil, inaugurou, em 1851, "o serviço de transporte de malas do correio britânico para o Brasil". E segundo Schwarcz (2007, p. 107),

[...] a rua do Ouvidor transformava-se no símbolo dileto dessa nova forma de vida em que se pretendia, nos trópicos, imitar a mesma sociabilidade das cortes ou dos mais recentes bulevares europeus. [...] durante os anos de 1840 a 1860 , que se cria uma febre de bailes, 
concertos, reuniões e festas. A corte se opõe à província, arrogando-se o papel de informar os melhores hábitos de civilidade [...].

Ainda conforme Schwarcz (2007, p. 110, destaque da autora), o Rio de Janeiro se tornou "um pólo centralizador e difusor de hábitos, costumes e até linguagens para todo o país, além de se transformar no cenário principal em que se desenrolava a dramatização da vida social da boa sociedade".

Nessa perspectiva civilizadora no Brasil com a chegada da Corte, o termo civilização estava presente nos discursos da elite política, literária e médica, o qual foi solidificado no período imperial, restringindo apenas a uma diminuta elite. Abreu (2002, p. 142) explicita a importância desse termo no Brasil:

[...] as razões e os motivos da civilização tornaram-se, ao longo do século XIX, uma obsessão a ser perseguida para a superação de todos os males e problemas do país, dentre eles, a forte presença da herança africana na aparência da população e em seus costumes. Dever-se-ia seguir os passos da parte da humanidade branca, tida como mais civilizada, e, se fosse possível, importar um pouco da própria Europa através da imigração. A civilização passou ser a meta do ensino e da formação profissional, implementada nos hábitos e costumes da população como um todo, exposta na aparência das cidades, em seu traçado, nas áreas de lazer e de serviços urbanos básicos. Enfim, precisava estar presente em todos os aspectos da sociedade, moldando os valores, as normas e os padrões não apenas das elites, mas também dos homens e mulheres livres.

Com o propósito explícito de civilizar a pequena elite imperial, a qual era composta por mulheres e homens de diferentes idades e escolarizados, sendo os detentores do controle da cultura erudita, os livros com o conteúdo sobre o comportamento para as mais diversas situações de convívio social foram um dos veículos do pensamento civilizador ${ }^{3}$, divulgando valores morais e códigos de conduta aos leitores interessados em adquirir novos modos de agir na sociedade, a exemplo de $O$ amigo da juventude; Tesouro da Paciência; $O$ amigo das mulheres; Avisos de uma mãe a seu filho; Instruções de uma mãe a sua filha; Tesouro de Meninas; Tesouro de Meninos; Instrução da Mocidade e Livro dos meninos, Recreação de um homem sensível; Tesouro de Adultas; Tesouro de Adultos; Aviso de uma mãe a sua filha; Cartas de uma mãe a seu filho; Instruções de um pai a seu filho; Instruções de uma mãe a seu filho; Lições de um pai a sua filha. Augusti (1998, p. 8) aponta a presença dessas obras na cidade do Rio de Janeiro, a exemplo "no mercado livreiro e, também, nos acervos de algumas bibliotecas fluminenses de uso coletivo, [as quais] vinham confirmar o interesse do público leitor em ter conhecimento sobre o comportamento considerado adequado às mais diversas situações de convívio social".

Outro veículo civilizador no Brasil se deu no campo educacional. D. Pedro I decretou a Lei de 15 de outubro de 1827, primeira lei sobre a instrução nacional do Império, a qual "manda criar escolas de primeiras letras em todas as cidades, vilas e lugares mais populosos do Império" (BRASIL, 1827). Conforme foram sendo criadas escolas pelo país, ainda que em números limitados, houve a necessidade de se ter instrumentos que auxiliassem na educação das crianças. A limitação de escolas de Primeiras Letras se deu por elas terem que existir somente em lugares populosos, como expõe a Lei supracitada, e com os parcos recursos que o Estado dispunha para a sua construção e contratação de professores, essas instituições ficaram restritas às crianças da diminuta elite (ALMEIDA, 1989; PINHEIRO, 2002; FARIA FILHO, 2003). No que diz 
respeito aos livros de leitura, os livros de origem estrangeira, em particular provenientes de Portugal, passaram também a circular nas escolas brasileiras (ARROYO, 1990), auxiliando os professores na educação e instrução das crianças.

Tendo em vista o caráter civilizador, exposto por Abreu (2002), que atravessava o país no século XIX, muitos livros de leitura do gênero literário da civilidade - composto por tratados de cortesia, manuais de savoir-vivre, regras de etiqueta e de conduta, elementos de moral, guias do bom-tom, cujo propósito era a modificação de comportamento das pessoas - circularam nas escolas, ensinando às crianças e, de um modo geral, às pessoas a se portarem na sociedade. A literatura da civilidade ensina aos leitores como se comportar em ambientes públicos, como agradar as pessoas, como jogar, como ser anfitrião, como conversar com as pessoas, como comer e etc. Embora a missão civilizatória fosse imprescindível à constituição e fortalecimento do Estado Nacional, ela exerceu um impacto moderado nas camadas ou classes populares de leitores e não leitores, haja vista a limitação desta classe nas escolas. Entretanto, faz-se necessário ressaltar que mesmo uma sociedade com escasso número de escolas não significa uma sociedade com ausência de leitura e escrita.

Dentre inúmeros títulos que circularam no país, a exemplo dos já citados, Tesouro de Meninos e Código do Bom-Tom ou Regras da Civilidade e de Bem Viver no Século XIX se fixaram no cenário educacional brasileiro, mais precisamente nas escolas de Primeiras Letras, no período imperial, por disseminarem arquétipos de comportamento para uma nação que estava em construção. Os livros do gênero de civilidade se fizeram presentes nas escolas de todo o Brasil, ensinando, ao mesmo tempo, as crianças a lerem e a escrevem e as regras de civilidade. Tais livros circularam nas províncias da Paraíba, da Bahia, do Rio Grande do Sul, do Rio de Janeiro, do Amazonas e do Pará (SENA, 2008).

Tesouro de Meninos foi escrito pelo francês Pierre Blanchard ${ }^{4}$. Embora se desconheça o registro da sua primeira edição, suponho que seja uma produção do século XVIII. A presença dessa obra no Brasil é datada do ano de 1808, tendo sido traduzida para a língua portuguesa pelo português Matheus José da Costa, já que a presença dessa obra no Brasil ocorreu em 1808, registrada através do pedido a Real Mesa Censória (ABREU, 2003). Quanto ao Código do Bom-Tom ou Regras da Civilidade e de Bem Viver no Século $X I X$, é da autoria do português José Inácio Roquette 5 , publicado em Portugal, em 1845. Freyre em Casa-Grande e Senzala assinala a circulação dessa obra no Brasil após a publicação, no entanto, não informa o período. Esta leitura foi recorrente para dar às crianças um "ar de europeus, não só deram para forrar os tetos das casas-grandes - até então de telha-vã - como para adotar regras de bom-tom francesas e inglesas as criações dos filhos. E adotá-las com exageros e excessos" (FREYRE, 1975, p. 420).

Essas duas obras, separadas pelo tempo e pela origem, são unidas pela temática que, desde o Renascimento, esteve em voga através d' O Cortesão (1528), de Baldassare Castiglione e A Civilidade Pueril (1530) ${ }^{6}$, de Erasmo de Rotterdam ${ }^{7}$. A influência da obra de Erasmo está expressa no prefácio de Tesouro de Meninos, mostrando aos seus leitores que a civilidade não é assunto novo, mas relevante para a sociedade, quando novos espaços de sociabilidade são criados. Já no século XIX, o Código do Bom-Tom de Roquette revela também os segredos de como as crianças devem agir na sociedade, oferecendo-lhes diversos conselhos, e entre eles, o da conversação. Na seção intitulada 'advertência', o autor indica que a sua filiação está nos livros nacionais e estrangeiros, bem como na sua "experiência acompanhada da reflexão. Tanto umas como outras são de muito freqüente aplicação no século em que vivemos [o XIX], e temos a firme convicção que nenhum mal virá a quem por elas se guiar" (ROQUETTE, 1997, p. 47). Para tanto, elejo a arte da conversação como objeto de análise desse estudo a fim de identificar as regras que os 
livros disseminaram aos leitores infantis da época para atuar na sociedade, como uma forma de clivagem social por meio da conversação, que tinha modos distintos para meninos e meninas, caracterizando-se como uma educação diferenciada para ambos os sexos.

\section{A arte da conversação em Tesouro de Meninos e Código do Bom-Tom}

Tesouro de Meninos e Código do Bom-Tom Tom ou Regras da Civilidade e de Bem Viver no Século XIX integram o grupo de tratados que abordam essa temática referente à sociabilidade. O precursor da literatura da arte da conversação é o livro italiano intitulado $O$ Cortesão (1528), marco fundador da conversação no Renascimento, por ser um período que remodelou hábitos e os propagou por séculos seguintes. Nessa perspectiva, Burke (1995) assinala 34 obras italianas, francesas e inglesas que tratam da arte da conversação entre os anos de 1528 a 1791. Isso mostra que esse gênero literário influenciou as obras que circularam no Brasil imperial.

A arte da conversação ganha importância no Brasil, mais precisamente na Corte, a partir dos novos espaços sociais que emergiram como festas, bailes, concertos, livrarias, cafés, confeitarias e a Rua do Ouvidor, os quais requeriam que as pessoas soubessem se relacionar através da conversação. Esses locais de sociabilidade se instalaram na Corte se tornaram os símbolos da civilidade, despertando nas pessoas, pertencentes à elite letrada $\mathrm{e}$ política ou próximas a elas, o interesse em freqüentá-los. Por tais espaços se configurarem como novidade, os brasileiros não sabiam se inserir neles, bem como desconheciam a arte de conversação. Pois, podemos compreender que "dominar as regras da civilidade representava de alguma maneira uma superioridade em relação aos outros estratos da sociedade" (RAINHO, 1995, p. 148).

Em Tesouro de Meninos e Código do Bom-Tom, os autores se utilizam do diálogo e da ficção como artifício para transmitir as regras de conversação. Dessa forma, eles introduzem personagens como o 'pai' para transmitir os ensinamentos de conduta aos seus dois filhos, sendo uma menina e um menino. No caso de Tesouro de Meninos, a sua forma da narrativa se apresenta por meio do diálogo. No que diz respeito às regras de civilidade, mais precisamente a conversação, esta ocorre sob a forma de tratado - normas escritas com objetivos de serem cumpridos, que nesse caso se referem às condutas. Nessa obra, há o Pai de Família, como assim é chamando na narrativa, Felícia com 11 anos e Paulino com 12 anos. Já em Código do Bom-Tom, as regras de conversação ocorrem por meio do gênero epistolar, cuja forma textual está presente em toda obra. Os personagens são compostos pelo pai, sem nome também, e por Teófilo, com oito anos de idade, e Eugênia, com seis anos. Assim, há uma nítida semelhança entre essas obras que se dá pelos personagens e pelo conteúdo, a arte da conversação. Embora os livros tratem da civilidade - das regras de convivência entre as pessoas na sociedade -, objetivo apenas apontar as regras sobre essa arte, comum nesses dois livros. Essas regras estão sob o título de 'Do modo por que nos devemos conduzir na conversação' em Tesouro de Meninos e 'Das assembléias' em Código do Bom-Tom. Dessa última, as regras foram "escritas de forma clara e didática", como toda a obra, introduzindo "seus leitores nas especificidades que marcavam a nova vida de sociedade" (ROQUETTE, 1997, p. 11).

No que se refere às regras de ambos os livros, as quais cabiam às crianças aprenderem para transitar na sociedade brasileira oitocentista, a recomendação é de que elas deviam permanecer caladas até que um adulto lhes autorizasse a falar. O silêncio se torna a primeira regra a ser aprendida pelas crianças, conforme os autores: "Escutai em silêncio se dizem coisas úteis, aproveitai-as; mas em nenhum caso mostrareis um ar 
fastioso ou distraído" (BLANCHARD, 1851, p. 184); "Recomendo-te muito, meu filho, que estejas muito tempo calado, e que nunca tenhas pressa de falar" (ROQUETTE, 1997, p. 127).

Segundo Burke (1995, p. 162), "o silêncio é em si um ato de comunicação", o qual aponta, através de La Rochefoucauld e de Morvan de Bellegarde, no século XVII, os diversos tipos de silêncio, sendo estes o silêncio de eloqüência, de zombaria, de respeito, de prudência, de ardil, de condescendência, de aprovação, de desprezo, de imbecil e de espirituosidade. Outra referência para o silêncio é muito anterior a esse período, quando Aristóteles (2002, p. 34), baseando-se em Sóflocles, afirma que, "um silêncio modesto acrescenta aos seus encantos". Tal afirmação de Aristóteles é dirigida às mulheres, o que evidencia que o silêncio é muito mais que um ato de comunicação, mas sinal de distinção de tratamento entre homens e mulheres. Para esse filósofo, ao homem cabia a audácia, a qual servia para comandar, e a mulher estava restrita à execução daquilo que o homem prescrevia.

$\mathrm{Na}$ perspectiva do silêncio ser mais restrito às mulheres conforme apontou Aristóteles, Baldassare Castiglione, em $O$ Cortesão (1528), e Erasmo de Rotterdam, em $A$ Civilidade Pueril (1530), mantiveram esse mesmo preceito. No primeiro livro, as mulheres não podiam participar do diálogo entre os homens para modelar o perfeito cortesão. A elas cabia assistir em silêncio à conversação. Já no segundo, o preceito estava claro na afirmação de Erasmo (1978, p. 95): "O silêncio é o melhor adorno das mulheres, e mais ainda das crianças".

O fato de Tesouro de Meninos evidenciar a influência d' A Civilidade Pueril, Blanchard emprega tal preceito na sua obra, ressaltando a distinção na conversação entre meninos e meninas. $\mathrm{O}$ emprego do silêncio para as meninas está exposto na passagem em que o autor exemplifica através do modelo de Madame Dacier ${ }^{8}$, considerada a mulher mais sábia do seu tempo:

Um cavalheiro Alemão, que nas suas viagens se comprazia em visitar as
pessoas do mais distinto merecimento, rogou a Madame Dacier que
escrevesse o seu nome sobre um livro de memória que trazia. Esta mulher
respeitável, depois de se haver escusado por algum tempo, escreveu por
fim o seu nome, e depois dele um verso de Sófocles, cujo sentido é que, o
silêncio é o mais belo ornamento da mulher. Eis aqui tens o teu modelo, ó
minha filha (BLANCHARD, 1851, p. 223 e 224, destaque do autor e
grifo meu).

Roquette também estabeleceu a regra da fala moderada como distinção entre os sexos, delimitando desde o momento em que a criança do sexo masculino ingressa em um ambiente que está na presença tanto de homens e de mulheres: "se na sociedade se achar alguma senhora de teu conhecimento, deves fazer-lhe teus cumprimentos, e depois retira-te para onde estão os homens, que nas grandes reuniões ficam quase sempre de pé" (ROQUETTE, 1997, p. 127). As orientações de Blanchard e de Roquette demarcaram o modelo de papéis femininos e masculinos de comportamento desde crianças na sociedade brasileira. Assim, cabia às meninas apenas conversar com as pessoas do mesmo sexo e a fala delas deveria ser moderada. O controle sobre a fala da mulher desde os primórdios da humanidade está associado à vergonha, à discrição e à moderação, cujas características deveriam ser próprias dela, como assegura Burke (1995). Nessa perspectiva, ele afirma: "uma mulher conversadeira poderia ser descrita como sfrenata di lingua (de língua desenfreada), como se os homens pensassem que ela precisasse de rédeas e freios em sua 
língua - uma punição por maledicência que era realmente aplicada em alguns lugares" (BURKE, 1995, p. 170).

O papel atribuído à mulher é posto desde cedo, conforme os livros apresentam. Outro compêndio que circulou no Brasil intitulado Tesouro de Meninas (1757), da autora francesa Pauline de Montmorin, conhecida como Madame Leprince Beaumont, ilustra bem, através da personagem Sensata, o papel que as mulheres devem desempenhar na sociedade. Essa personagem é prudente, discreta, possui bom senso e só fala quando é solicitada pela sua mestra ou por outras pessoas que lhe fazem alguma pergunta.

O conselho dado por Blanchard, a respeito do silêncio às mulheres, se coaduna com o de Roquette (1997, p. 130), quando este recomenda que:

E tu, minha Eugênia, ainda com mais razão deves entrar na sala modesta e silenciosamente, e fazer com que não chames sobre ti a atenção dos circunstantes; e quando aconteça o contrário, ao menos que não seja nunca por gargalhada de riso, ou caretas e trejeitos, ou outras coisas semelhantes que anunciem desejas fixar a atenção dos circunstantes.

Outra recomendação do autor, dada à menina, está também na perspectiva do modelo feminino para a época, conforme apontei através de Tesouro de Meninas acima:

Se te achares cercada de senhoras que não conheces, espera que elas te falem, e responde-lhes singelamente e com voz branda, mostrando-te reconhecida ao seu grado. Se se calarem, cala-te também (ROQUETTE, 1997, p. 130).

É indecoroso a uma menina ocupar-se dos homens. Se algum dos que estão na sociedade lhe falar, deves responder-lhe com polidez e recato, mas de modo que as pessoas que estiverem ao pé de ti ouçam o que dizes. Olha com gravidade, mas não ponhas os olhos no chão, que é afetação; mas quando falares, ou quando dançares, olha para o ombro daquele que te fala. (ROQUETTE, 1997, p. 131).

Embora coubessem às mulheres e às crianças o silêncio e uma fala comedida, o cultivo da conversação entre as crianças mostra a importância da inserção delas no mundo sociável - a intimidade familiar e a vida pública. No Brasil do século XIX, as ocasiões do mundo sociável eram almoços, jantares, chás, visitas, a escola, as livrarias e outros espaços urbanos que foram criados ao longo desse período.

Outra questão que está relacionada à conversação é a dissimulação dos sentimentos. As prescrições de Roquette e de Blanchard estão nessa perspectiva, embora cada um estabeleça a sua maneira: "Se te divertires, não mostres senão uma alegria moderada; se estiveres aborrecida, dissimula e não o dês a conhecer; reprime os bocejos, e felicita-te de saberes preferir o estudo e a vida doméstica aos passatempos mundanos" (ROQUETTE, 1997, p. 131); e "Levai à Sociedade um ar doce, cortês, até mesmo alegre" (BLANCHARD, 1851, p. 201). Essas prescrições revelam o uso de "máscara" (STAROBINSKI, 2001), a qual a criança deve saber usar para agir corretamente na sociedade. Se, por um lado, o uso de máscaras se configura como a dissimulação para encobrir os verdadeiros sentimentos, por outro, faz-se necessário o seu uso, já que "a vida ter-se-ía tornado intolerável, sobretudo nas condições de promiscuidade física da época, se o costume não impusesse à casa uma certa disciplina" (ARIÈS, 1978, p. 14). É através das máscaras, sob o código da civilidade, que se firma o laço social entre as pessoas. 
Os tópicos de conversação, ou seja, os temas para serem tratados nos encontros com as pessoas, apresentam-se como conselhos dados às crianças. Segundo Roquette (1997, p. 163), quando a criança freqüentar a casa de outras pessoas, é necessário que ela fale coisas "decentes e honestas", dê algumas notícias que saiba, "pedir informações sobre alguma coisa ou pessoa, e até sobre usos e costumes". Os detalhes dos seus conselhos são revelados às crianças do seguinte modo:

\begin{abstract}
"Em casa de enforcado, não se fala em corda", é um provérbio que, assim como todos os ditados populares, encerra uma grande ensinança: sem vos mostrardes curiosos, buscai saber com disfarce a história das pessoas cuja casa freqüientais; porque numa casa não se deve falar de bancarrota, noutra, de divórcio; nesta, de apostasia; naquela de demanda por causa de um testamento, dum contrato falsificado: que sei eu? Todas as paixões, todos os vícios da humanidade, todas as misérias, sublevam-se muitas vezes por uma palavra imprudente (ROQUETTE, 1997, p. 170, destaque do autor).
\end{abstract}

A orientação de Blanchard está na mesma direção da de Roquette, de modo que ele recomenda que a criança deva estudar o humor da pessoa a quem dirige a conversação, para nada dizer que lhe cause pena e, ao contar algo, não se detenha muito para não cansar as pessoas, fazendo uso da fala simples e agradável. De acordo com Starobinski (2001, p. 62 e 63, destaques do autor), as regras sobre os tópicos de conversação requerem:

a exclusão não apenas das pessoas "de má companhia", mas também de certo número de assuntos de conversação (não se falará de dinheiro, nem de sua mulher etc.), e das palavras "suspeitas", das expressões "baixas" etc. Assim, dispõe-se de um princípio de seleção que se baseia na "regra" e no "bom uso"; as pessoas serão preferidas segundo o emprego "elegante", "delicado", que fazem dos recursos da linguagem; a escolha que dirigem aos melhores vocábulos as assinala à atenção da "melhor sociedade". A fala "pura", "depurada", é considerada como indicativo das virtudes da pessoa.

A linguagem, assim marcada, não perderá nada de sua função referencial, mas terá como função acessória qualificar seus usuários, representá-los em um universo de convenções onde importa empenhar apenas o melhor de si...

Considerando que a boa linguagem corresponde às boas atitudes, na conversação era recriminado proferir palavras desonestas. Por isso, Blanchard (1851, p. 187) orienta seus filhos para que "não saiam jamais da vossa boca palavras desonestas: se outrem deixar escapar alguma na vossa presença, calai-vos, fazei entender somente pelo vosso ar, que isso vos aflige".

Outra regra imposta às crianças, a respeito da arte da conversação é sobre a interrupção nas conversações que, no ponto de vista de Blanchard, é algo condenável. De acordo com Burke (1995, p. 140), "a interrupção era um pecado", já que "os autores seculares também aconselhavam seus leitores a não interromper". Ele ilustra essa afirmação por meio da regra propagada por muitos autores: "É necessário esperar a própria vez". Seguindo essa regra, Blanchard alerta os personagens infantis: "nunca deveis obrigar a pessoa que fala a fazer repetições, dizendo-lhe: Como? Que dizeis? Eu não vos entendo, ou outras palavras semelhantes" (BLANCHARD, 1851, p. 189). Igual restrição é: "Enquanto sois pequenos não vos deveis meter na conversação das pessoas já feitas" (p. 
184). Ou ainda: "Se alguém fala, deixai-o acabar o que tem para dizer: nada há tão incivil como cortar o discurso aos outros" (p. 185). Essa orientação sobre a interrupção não está expressa deliberadamente em Código do Bom-Tom, mas pode ser vista no momento em que Roquette, sob a figura do pai, recomenda que os filhos falem moderadamente e fiquem em maior parte em silêncio. Isso significa um modo de evitar a interrupções no diálogo.

Ainda com o objetivo de evitar a interrupção, há a regra de falar somente quando for solicitado, a qual é expressa para ambos os sexos, conforme os autores dos manuais. Tal regra está posta na passagem bíblica em Eclesiástico (32:7-9), onde há um pequeno código de boas maneiras a respeito de banquetes:

Fale, jovem, se for necessário, mas apenas umas duas vezes, quando interrogado. Resuma o que tem a dizer e diga muito em poucas palavras. Seja como alguém que sabe, mas se cala. Não procure impor-se no meio dos grandes, nem fique tagarelando enquanto outro fala.

Mas a prescrição sobre a fala também está na sua forma que deve ser moderada, conforme já apontei anteriormente: "Quando falardes, seja em tom moderado, nem muito alto; nem muito baixo; fazei-o de sorte que vossos discursos sejam agradáveis, honestos e sem afetação" (BLANCHARD, 1851, p. 185). Roquette (1997, p. 130) orienta que a forma deve ser "singelamente e com voz branda, mostrando-te reconhecida ao seu grado" e que os cumprimentos "não sejam longos nem em voz muito alta" (ROQUETTE, 1997, p. 125). $\mathrm{O}$ autor ainda sugere algumas expressões para serem proferidas ao cumprimentar uma senhora em ocasião de anos ou de parabéns:

\begin{abstract}
"Estimo, minha Senhora, que Vossa Senhoria, Excelência etc., tenha tão grandes motivos de gosto, e que os conte muitas vezes..." ou simplesmente: "Dou a Vossa... os parabéns pelo dia de hoje". Sendo por ocasião do regozijo, podes dizer: "Minha Senhora, dou a V. S a etc., os parabéns por esta grande felicidade etc., ou outras expressões semelhantes. Ao que a senhora pode responder: "Agradeço a V. S ${ }^{a}$ etc., o obséquio que me faz..., as expressões com que me trata... com que me lisonjeia..., os testemunhos que me dá do seu contentamento..., o interesse que toma pelo que me pertence... etc., fico bem persuadida do quanto devo a V. $\mathrm{S}^{\mathrm{a}}$ etc., à atenção etc." e semelhantes cumprimentos (ROQUETTE, 1997, p. 125, destaque do autor).
\end{abstract}

Os autores também prescrevem que as conversas devem ocorrer com os seus pares, sejam eles do mesmo sexo, idade e da condição social. Para Burke (1995, p. 139), essa regra está relacionada "à necessidade de se comportar de maneira diferente diante de pessoas com posições diferentes na hierarquia social", de modo que o interlocutor deverá procurar pessoas apropriadas para manter o diálogo recíproco, ou quando não for possível, adaptar a conversa a cada grupo de pessoas. Nessa perspectiva, Blanchard (1851, p. 187) recomenda: "ajustai a conversação com o tom da sociedade em que vos achardes", bem como "Deveis, pelo contrário, ter atenção em deixar brilhar cada um no que sabe, e proporcionar os discursos com os conhecimentos e a inteligência das pessoas que se entretem conosco" (p. 188). 


\section{Considerações finais}

As prescrições de Tesouro de Meninos e Código do Bom-Tom sobre a arte de conversar, expostas aqui, recuperam um modelo já posto por outros manuais renascentistas a exemplo de $O$ Cortesão e A Civilidade Pueril. As regras apontadas por Blanchard e Roquette em seus livros se configuram em lições que precisavam ser aprendidas para o uso na sociedade brasileira, que eram desprovidas de regras de civilidade. Tais regras demonstram os modelos de sociabilidades que foram favorecidas e impulsionadas pela criação de escolas, evidenciando o projeto civilizatório iniciado ainda no final do período colonial, mas que somente foi solidificado no Império. Com objetivos claros de refinar os hábitos das pessoas, esses livros buscavam refrear as atitudes e os sentimentos delas desde a tenra idade, através das máscaras da civilidade, por eles terem sidos destinados, primeiramente, às crianças, conforme os personagens infantis nas narrativas, embora saibamos que os destinatários dessas obras são mais amplos do que o público infantil. Pois, o destinatário implícito dessas obras é todo aquele interessado em participar do comércio da sociedade, sejam mulheres e homens de diferentes idades e alfabetizados, pertencentes de uma diminuta elite. Possuidores desse conhecimento, eles se tornariam divulgadores das regras do jogo social, o que distinguiriam dos demais.

Assim, tornar visíveis as regras de conversação de Tesouro de Meninos e Código do Bom-Tom livros que circularam pelas mãos dos leitores das escolas de Primeiras Letras no Brasil imperial nos faz perceber onde repousam as regras de conversação que ainda permanecem valendo nos dias de hoje, porém de outro modo: na oralidade. Investigar o passado por meio desses manuais implica em reconhecê-los como uma "poderosa fonte de conhecimento da história de uma nação [...]" (LAJOLO e ZILBERMAN, 1998, p. 121), bem como na ordenação do mundo da leitura no Brasil.

\section{Referências}

ABREU, Márcia. Caminhos do livro. Campinas: São Paulo: Mercado das Letras, 2003.

ABREU, Martha. Civilização. In: VAINFAS, Ronaldo (Org.). Dicionário do Brasil Imperial (1822 - 1889). Rio de Janeiro: Objetiva, 2002.

ALENCASTRO, Luiz Felipe. Vida privada e ordem privada no Império. In: ALENCASTRO, Luiz Felipe (Org. do volume). História da Vida Privada no Brasil: Império. São Paulo: Companhia das Letras, 1997. (Vol. 2).

ALMEIDA, José Ricardo Pires de. História da Instrução Pública no Brasil (1500-1889). Trad. Antonio Chizzotti. São Paulo: EDUC, 1989.

ARIÈS, Philippe. Prefácio. In: ERASMO. Civilidade Pueril. Estampa. Lisboa, 1978.

ARISTÓTELES. Política. São Paulo. Martin Claret, 2002.

ARROYO, Leonardo. Literatura Infantil Brasileira. Melhoramentos. São Paulo, 1990.

AUGUSTI, Valéria. O romance como guia de conduta: A moreninha e Os dois amores. Dissertação. Instituto de Estudos da Linguagem. Unicamp, 1998. 
AZEVEDO, André Nunes de. Da monarquia à república: um estudo dos conceitos de civilização e progresso na cidade do Rio de Janeiro entre 1868 a 1906. Tese de doutorado. Pontifícia Universidade Católica do Rio de Janeiro, 2003.

CASTIGLIONE, Baldassare. O Cortesão. Trad. Carlos Louzada. São Paulo: Martins Fontes, 1997.

BARBOSA, Socorro de Fátima P. Jornal e Literatura: a imprensa brasileira no século XIX. Porto Alegre: Nova Prova, 2007.

BEAUMONT, Madame Leprince. Tesouro de Meninas. Trad Joaquim Ignácio Frias. Lisboa, 1846. Disponível em: http://www.caminhosdoromance.iel.unicamp.br/. Acesso em: 19 de julho de 2007.

BLANCHARD, Pierre. Tesouro de Meninos. Trad. Matheus José da Costa. 6 ed. Lisboa, 1851. Disponível em: http://www.caminhosdoromance.iel.unicamp.br/. Acesso em: 19 de julho de 2007.

BRASIL. Lei de 15 de outubro de 1827. Disponível em: http://www.pedagogiaemfoco.pro.br/heb05a.htm. Acesso em: 16 de julho de 2010.

BURKE, Peter. A arte da conversação. Trad. Álvaro Luiz Hatnher. São Paulo: UNESP, 1995.

CHARTIER, Roger. Distinção e divulgação: a civilidade e seus livros. In:

Leituras e leitores na França do Antigo Regime. Trad.Álvaro Lorencini. São Paulo: UNESP, 2004.

DICIONÁRIO BIBLIOGRÁFICO PORTUGUÊS. Estudos de Innocencio Francisco da Silva aplicaveis a Portugal e ao Brasil. Continuados e ampliados por P. V. Brito Aranha. Revistos por Gomes de Brito e Álvaro Neves, Lisboa: Imprensa Nacional, 23 vol., 18581923.

ECLESIÁSTICO. In: BÍBLIA SAGRADA. Traduzida em Português por João Ferreira de Almeida. Revista e Corrigida. São Paulo: Sociedade Bíblica do Brasil, 1995.

ERASMO. A Civilidade Pueril. Trad. Fernando Guerreiro. Lisboa: Editorial Estampa, 1978.

FARIA FILHO, Luciano. A instrução elementar no século XIX. In: LOPES, Eliane; FARIA; FILHO, Luciano; VEIGA, Cynthia (Org.). 500 anos de educação no Brasil. Belo Horizonte: Autêntica, 2003.

FERREIRA, Tânia M. Tavares Bessone da Cruz. Os livros na imprensa: as resenhas e a divulgação do conhecimento no Brasil na segunda metade do século XIX. In: CARVALHO, José Murilo (Org.). Nação e cidadania no Império: novos horizontes. Rio de Janeiro: Civilização Brasileira, 2007. 
FREYRE, Gilberto. Casa-grande e Senzala: a formação da família brasileira sob o regime da economia patriarcal. 17. ed. Rio de Janeiro: José Olympio, 1975.

LAJOLO, Marisa e ZILBERMAN, Regina. A Formação da Leitura no Brasil. 2. ed. São Paulo: Ática, 1998.

MATTOS, Ilmar Rohloff de. O tempo saquarema. 5. ed. São Paulo: Hucitec, 2004.

PINHEIRO, Antônio Carlos Ferreira. Da era das cadeiras isoladas à era dos grupos escolares na Paraíba. Campinas: Autores Associados, 2002.

RAINHO, Maria do Carmo Teixeira. A distinção e suas normas: leituras e leitores dos manuais de etiqueta e civilidade - Rio de Janeiro, século XIX. ACERVO: revista do Arquivo Nacional. V. 8, n. 1-2 (jan/dez. 1995) - Rio de Janeiro: Arquivo Nacional, 1995.

REVEL, Jacques. Os usos da civilidade. In: ARIÈS, Philippe e CHARTIER, Roger (Org). Da Renascença ao Século das Luzes. Trad.Hildegard Feist. São Paulo: Companhia das Letras, 1991.

ROQUETTE, J. I. Código o Bom-Tom, ou, Regras da Civilidade e de Bem Viver no Século XIX. Organizado por Lilia Moritz Schwarcz. São Paulo: Companhia das Letras, 1997.

SCHWARCZ, Lilia Moritz. As barbas do Imperador: D. Pedro II, um monarca nos trópicos. 2. ed. São Paulo: Companhia das Letras, 2007.

SENA, Fabiana. A Tradição da Civilidade nos Livros de Leitura no Império e na Primeira República. Tese de doutorado. Programa de Pós-graduação em Linguística, UFPB, 2008.

SODRÉ, Nelson Werneck. A imprensa colonial. In: História da imprensa no Brasil. 4. ed. Rio de Janeiro: Mauad, 1999.

STAROBINSKI, Jean. As máscaras da civilização: ensaios. Trad. Maria Lúcia Machado. São Paulo: Companhia das Letras, 2001.

TOBIAS, José Antônio. História da Educação Brasileira. 3. ed. São Paulo: IBRASA, 1986.

1 Prof $^{a}$ Dr $^{a}$ no Centro de Educação da Universidade Federal da Paraíba. Doutora pela Universidade Federal da Paraíba. Membro do HISTEDBR/PB.

2 Sodré (1999, p. 18, destaque do autor) esclarece que a civilização não fazia parte do Brasil-Colônia, mais especificamente antes da chegada da Família Real: "No dizer de Moreira de Azeredo, "não convinha a Portugal que houvesse civilização no Brasil. Desejando colocar essa colônia atada ao seu domínio, não queria arrancá-la das trevas da ignorância". A ignorância, realmente, constituiu imperiosa necessidade para os que exploraram os outros indivíduos, classes ou países. Manter as colônias fechadas à cultura era característica própria da dominação. Assim, a ideologia deve erigir a ignorância em virtude."

3 Durante o século XIX o jornal também se configurou como um veículo do pensamento civilizador (BARBOSA, 2007; FERREIRA, 2007). 
4 Não foi possível localizar informações sobre o autor. Posteriormente, ele publicou outro livro de título similar, diferenciando o subtítulo que fornece o assunto da obra. Tesouro de meninos: resumo de história natural para uso da mocidade de ambos os sexos, e instrução das pessoas que desejam ter noções da história dos três reinos da natureza. Compilado e ordenado por Pedro Blanchard, e traduzido em português com muitas correções e artigos novos por Matheus José da Costa. Lisboa, na Imp. Regia 8. 6 tomos com estampas. O tomo $1 .^{\circ}$ publicado em 1814, contém a Cosmografia e Mineralogia. - O tomo 2. ${ }^{\circ}$, 1815, a Botânica. - O 3. ${ }^{\circ}, 1817$, Zoologia, mamíferos. - O 4. ${ }^{\circ}$, ibi, Continuação dos mamíferos, aves. - O 5., 1819 , Continuação das aves, peixes. - O 6. ${ }^{\circ}, 1830$, Continuação dos peixes, crustáceos, testásseis, répteis, vermes, insetos, polipos, zoófilos, etc. - A nomenclatura portuguesa adotada nesta obra foi disposta pelo insigne Brotero. (DICIONÁRIO BIBLIOGRÁFICO PORTUGUÊS DE INNOCENCIO FRANCISCO DA SILVA, $\mathrm{s} / \mathrm{d})$.

5 José Inácio Roquette natural Alcabideche, Portugal. Ingressou na vida eclesiástica em 1821. Viveu em Londres e em Paris. Em Paris, obteve bom acolhimento, não só do embaixador, que então era o Ex.mo Visconde da Carreira, mas do Arcebispo de Paris, que para logo lhe forneceu alguns meios de subsistência, colocando-o em uma freguesia do bairro de S. Germano; bem que pouco serviço pudesse aí prestar, em razão de faltar-lhe o uso e a pratica da língua francesa, para que houve mister tempo, até chegar a pregar correntemente e com desembaraço. Deu-se então á tradução e composição de varias obras, com o fim de tornar-se prestável aos seus compatriotas, e também de recolher para si maiores recursos do que podiam provir-lhe dos escassos proventos do ministério eclesiástico. Tornou-se cavaleiro da Ordem Imperial da Rosa, conferida por S. M. o Imperador do Brasil em 3 de Setembro de 1847. As obras por ele compostas, traduzidas ou coordenadas, versam sobre assuntos místicos, e de erudição e literatura sagrada, eclesiástica e profana (DICIONÁRIO BIBLIOGRÁFICO PORTUGUÊS DE INNOCENCIO FRANCISCO DA SILVA, $\mathrm{s} / \mathrm{d})$.

6 A respeito das edições das obras O Cortesão e A Civilidade Pueril, utilizo, para esse artigo, as edições de 1997 e 1978, respectivamente.

7 Cf. Chartier (2004), Revel (1991) e Sena (2008).

8 Seu nome original é Anne Le Fèvre Dacier, (1654 - 1720). Nasceu na França. Durante a sua vida foi conhecida como Madame Dacier. Ela foi tradutora de clássicos, como de Terêncio, Platão e Aristóteles.

Artigo recebido em: 07/03/2009

Aprovado para publicação em: 01/08/2009 